\title{
HOAKS, POLITIK, DAN RISIKO MASYARAKAT MODERN
}

\author{
HOAX, POLITICS, AND MODERN RISK SOCIETY
}

\author{
LASARUS JEHAMAT ${ }^{*}$, YOSEF EMANUEL JELAHUT ${ }^{1}$, DASMA A. DAMANIK ${ }^{1}$ \\ ${ }^{1}$ Program Studi Sosiologi Fisip Undana- Kupang \\ *Email: lasarus.jehamat@staf.undana.ac.id
}

\begin{abstract}
Abstraksi
Ruang sosial Indonesia dalam setahun terakhir dipenuhi fenomena hoaks (berita bohong). Fenomena hoaks berkembang seiring dengan menguat dan mengentalnya poros politik nasional. Masyarakat tidak disuguhi oleh berita yang benar tetapi diisi oleh berbagai luapan emosi. Implikasinya, masyarakat terbelah ke dalam kelompok-kelompok kecil berbasis kepentingan. Hal ini menyebabkan ruang sosial dan budaya kaku dan rigid. Oleh Ulrich Beck, fenomena seperti itu disebut masyarakat berisiko. Risiko muncul tidak saja karena perkembangan teknologi dalam nalar fisik tetapi juga karena praktik sosial dan politik yang keliru. Dalam perkembangannya, politik Indonesia mengikuti trend pengentalan ke dalam kelompok. Masyarakat yang terbelah ke dalam kelompok berpotensi memperkuat integrasi internal. Akibatnya, tingkat adaptasi eksternalnya menjadi rendah. Politik disebut wilayah yang paling rentan dan karena itu bertanggung jawab atas keterpecahan sosial tersebut. Karena politik, elemen masyarakat menjadikan media sosial tidak saja sebagai alat tetapi juga tujuan akhirnya. Di sana, masyarakat melakukan berbagai gerakan provokasi berita yang kebenarannya sungguh diragukan. Realitas seperti itu menuntut tanggung jawab negara dalam mengelolah media. Pengelolahan media tidak sama dengan mengontrol media. Mengelola media ialah memberikan pendidikan literasi tidak saja kepada media dan elite politik tetapi juga kepada masyarakat kebanyakan. Nalar rasional masyarakat Indonesia harus terus diasah untuk sebuah bangsa Indonesia yang beradab.
\end{abstract}

Kata kunci: hoaks, masyarakat berisiko, politik, bangsa, dan masyarakat

\begin{abstract}
Indonesia's social space in the past year has been filled with the phenomenon of hoax. The phenomenon of hoax develops along with the strengthening and thickening of the national political axis. Society is not treated by true news but it is filled with various emotional outbursts. The implication is that the community is divided into small groups based on interests. This causes the social and cultural space to be rigid and inflexible. By Ulrich Beck, such phenomena are called risk society. Risks arise not only because of technological developments in physical reason but also because of erroneous social and political practices. In its development, Indonesian politics follows the trend of thickening into groups. A society divided into groups has the potential to strengthen internal integration. As a result, the level of external adaptation is low. Politics is called the most vulnerable region and is therefore responsible for social divisions. Because of politics, elements of society make social media not only a tool but also their ultimate goal. There, the people practice various news provocation movements the truth of which cannot be verified. Such reality demands state responsibility in managing the media. Media management is not the same as controlling media. Managing the media is providing literacy education not only to the media and the political elite but also to the general public. Consequently, the logical reasoning for the existence of a civilized Indonesian society should be honed contiously.
\end{abstract}

Keywords: hoax, risk society, politics, nation, society 


\section{PENDAHULUAN}

Hoaks seperti sangat seksi di jagat sosial dan media akhir-akhir ini. Oleh hampir semua kalangan, hoaks bak hantu yang bergentayangan dan siap masuk ke otak dan pikiran manusia. Hoaks seperti setan penghancur ketenangan dan penjahat tak kelihatan. Karena kerja yang demikian maka hoaks seperti musuh yang harus segera dibasmi. Bangsa Indonesia akhirnya kelimpungan karena hoaks.

Bagaimana fenomena hoaks dapat dipahami di ruang sosial? Hoaks harus ditempatkan sebagai salah satu risiko masyarakat modern. Meminjam Beck, Lash, dan Wynne (1992), selain sebagai fenomena hipokriditas, hoaks adalah bentuk lain dari apa yang disebut risiko itu. Eksistensi media dan gelombang kebebasan yang masif jika tanpa kontrol, akan menghasilkan risiko sosial baru dalam masyarakat.

Tulisan ini tidak sedang memperkarakan makna hoaks dan mendiskusikan bahasa di sini. Yang ingin dibahas di sini ialah fenomena hoaks yang terjadi dalam dunia politik menjadi sangat berrisiko bagi masyarakat modern.

Untuk tujuan itu, yang harus diperiksa pertama adalah semua lembaga sosial apa pun itu terlebih dahulu termasuk negara. Negara harus diperiksa pertama. Ketakutan banyak pihak ialah hoaks muncul karena negara terlalu banyak berbohong selama ini. Hoaks berkembang karena banyaknya 'praktik bohong' yang dilakukan elit kekuasaan. Jika negara bisa mengelolah diri maka masyarakat dan media sosial akan segera mengikuti watak Negara (Ramamurthy and Shanze, 2001).

Oleh karena itu, fenomena hoaks harus pula menganalisis konteks terjadinya hoaks. Itu berarti, fenomena politik lokal dan nasional Indonesia laik dianalisis. Dianalisis karena jika masyarakat masuk ke dalam realitas seperti itu maka masyarakat tersebut masuk dalam kategori berisiko.

Adalah ahli bernama Ulrich Beck yang pertama kali menyebut masyarakat modern saat ini sebagai masyarakat berisiko. Disebutkan demikian karena ternyata modernitas dan produk yang dihasilkannya telah menyebabkan tidak saja perkembangan masyarakat ke arah yang baik tetapi justru lebih banyak yang buruk.
Beck (1992) dalam Risk Society: Towards a New Modernity mengatakan bahwa manusia rasional yang memproduksi beragam teknologi kadang-kadang tidak mampu mengantisipasi dampak negatif perkembangan teknologi itu. Banyak produk teknologi manusia rasional yang lebih berdampak menghancurkan. Peradaban memang semakin berkembang. Meski demikian, perkembangan peradaban justru meruntuhkan sisi kemanusiaan manusia. Itulah risiko masyarakat berisiko.

Beck menyebut ketidakadilan dalam distribusi kesejahteraan, pengetahuan, status dan kelas, konflik sosial, individualisasi, institusionalisasi dan standarisasi merupakan beragam risiko yang ditimbulkan karena geliat modernitas tanpa kontrol. Pernyataan Beck tentang risiko masyarakat modern hampir mendapatkan kepenuhannya saat ini. Pernyataan Beck nyaris terlihat pijakannya di ruang sosial modernitas baik di aspek budaya, ekonomi dan juga di dunia politik masa kini.

Beck sebenarnya ingin menjelaskan realitas perkembangan dunia yang diproduksi oleh akal manusia rasional. Modernitas merupakan produk andalan masyarakat rasional itu. Dengan kekuatan akal, manusia bisa menghasilkan banyak sekali teknologi. Implikasinya, manusia hidup dalam realitas yang dikonstruksi. Dalam kondisi demikian, semua hal dapat dilakukan termasuk memupuk fenomena manipulasi (hipokriditas).

Masyarakat modern tengah disuguhi oleh beragam kebohongan. Politik menjadi wilayah yang paling rentan akan kebohongan itu. Dua sebab mengapa politik dianggap paling rentan.

Pertama, secara sempit, politik adalah mekanisme untuk mencari dan mendapatkan kekuasaan. Di soal ini, setiap yang ingin berkuasa akan melakukan apa pun agar kekuasaan dapat digenggam. Secara normatif, beragam cara mendapatkan kekuasaan telah diatur dan sudah menjadi kesepakatan bersama.

Soal menjadi lain ketika idealisme aturan tidak pernah dipraktikan di level sosial. Dalam praktiknya, banyak politisi menggunakan cara yang tak lazim dan jauh dari mekanisme yang telah disepakati bersama. Di situ, politik kebohongan 
mendapatkan pijakannya.

Kedua, kampanye politik merupakan arena di mana semua entitas kekuasaan berusaha meyakinkan konsumen politik di pasar politik. Di sana, hukum pemasaran menjadi basis utama. Setiap yang bisa melakukan pemasaran isu akan mendapatkan pelanggan dan konsumen.

Jika ditarik masuk ke kanal politik, setiap yang bisa mengemas isi dan isu kampanye, apa pun caranya, dapat merebut suara rakyat. Karena itu maka dalam ruang kampanye, semua cara digunakan untuk tujuan kekuasaan. Termasuk di dalamnya ialah penggunaan cara-cara politik kebohongan untuk mendapatkan simpati rakyat.

Realias politik kebohongan di Indonesia masa kini, persis disampaikan Runciman (2008). Runciman menyebut jika politik kekinian cenderung menunjukan sebuah gejala yang disebut hipokrit. Dalam Political Hypocrisy: The Mask of Power, From Hobbes to Orwell and Beyond, Runciman (2010) mengatakan bahwa hipokriditas merupakan sebuah realitas kebohongan dalam politik.

Kebohongan justeru terjadi secara banal dan vulgar. Disebut banal dan biasa karena perilaku elite politik kerap menunjukan watak manipulatif, menipu, dan terus membohongi masyarakat ketimbang mempresentasikan watak aslinya.

Dalam logika seperti itu, elite kerap bermain di dua panggung seperti disampaikan Goffman. Panggung depan dan panggung belakang. Jika di panggung depan disampaikan hal-hal positif, tidak demikian halnya dengan panggung belakang. Yang disampaikan di depan sama sekali tidak merepresentasi watak politisi di panggung belakang. Di sana, wajah kebohongan nampak dengan sangat vulgar.

Fakta banalitas kebohongan tergambar jelas dalam fenomena hoaks. Hasil riset Mafindo (2018) menunjukan hoaks tumbuh subur di republik ini. Dalam tiga bulan, hoaks dan berita bohong menunjukan trend peningkatan. Pada Juli 2018, berita hoax sekitar 61,54\%, Agustus 63,3\% dan September $74,42 \%$.

Menurut penelitian lembaga ini, sebagian besar berita hoax diisi dengan konten politik. Di bulan Juli, berita hoax dengan konten politik sebesar 46,38\%, Agustus, 58,42\% dan September sebesar 68,44\%. Dari aspek media (tools), sebagian besar hoax disalurkan melalui media sosial.

Data di atas menunjukan bahwa kebohongan memang tengah menghiasi perjalanan politik bangsa ini. Tren peningkatan hoaks dari waktu ke waktu khas menggambarkan watak manusia politik Indonesia.

Menyebut manusia politik, bayangan utama tentu harus tertuju pada sekelompok elite politik dan massa yang terus mengumbar isu dan gosip untuk tujuan kekuasaan. Karena realitas demikian, Weaver (2008) menyebutnya sebagai jebakan hipokrisi. Weaver mengatakan bahwa hipokriditas muncul ketika yang disampaikan di mulut berbeda dan bertolak belakang dengan praktiknya di masyarakat.

Untuk mensosialisasikan janji, rakyat dipengaruhi dengan beragam kebohongan. Benar pengumbar itu menggunakan data. Masalahnya, data yang disodorkan kadang menjadi amat subyektif. Padahal, yang dibutuhkan adalah data yang benar-benar obyektif. Data obyektif ialah yang keluar di mulut sama dengan yang terjadi di lapangan. Jika tidak, kebohongan menjadi gejala utama di sana.

Dalam studi sosiologi media, setiap orang berhak mempromosikan dirinya melalui alat komunikasi tertentu. Melalui media dan dalam forum tertentu, seseorang yang ingin mendulang hasil positif dalam konteks kekuasaan, ternyata harus benar-benar keluar dari sifat aslinya. Inilah yang oleh Baudrillard (1983) disebut sebagai hiperrealitas.

Di mana pun, gejala hiperrealitas tidak selalu memberikan kontribusi substantif. Masyarakat modern memang telah menjadikan media sebagai menu harian. Paradoks utama menurut Baudrillard adalah ketika masyarakat modern yang semakin rasional itu justru terjebak oleh kerja-kerja irrasional.

Masyarakat begitu mudah menerima realitas simbolis dalam media ketika sibuk menganalisis kerja riil seseorang di realitas sosial. Inilah kehebatan media dan kesalahan fatal manusia rasional. Selanjutnya, ketika seseorang menggunakan hal-hal lain yang berada di luar batas kewajaran manusiawi, 
perkara dasarnya adalah manipulasi dalam relasi kekuasaan (Adejumobi, 2011).

Di situ, kepercayaan masyarakat kepada politik dan elite politik perlu disebut. Dalam Trust and Rule, Tilly (2005) mengatakan pentingnya menghubungkan kepercayaan dengan aturan dalam konteks politik publik. Dalam politik publik, politik menjadi sangat kontroversial. Sebab utamanya karena di sana terdapat begitu banyak kepentingan individu dan atau kolektif, klaim antaraktor politik, kepentingan pemerintah, penguasa dan agen korporasi.

Disana, jaringan kepercayaan, segmen jaringan kepercayaan, dan anggota jaringan kepercayaan terlibat efektif dalam politik kontroversial. Sebab, mereka adalah entitas yang membuat klaim apa pun bentuk klaim dan isi klaim yang dilakukan.

Objek klaim dan sebagai pihak ketiga untuk mengklaim pembuatannya. Dalam pandangan Tilly, klaim dapat juga dipahami sebagai otoritas dan wewenang pembuat aturan dan lain-lain. Dengan otoritas demikian, pemilik kekuasaan yang banyak kepentingan itu berusaha agar kepentingannya bisa diakomodir dengan cara apa pun.

Selanjutnya, dalam The Political Economy of Trust, Farrel (2009) menyebutkan bahwa kekuasaan saat ini hanya dapat dipahami sejauh memahami pembangunan dan pembentukan jaringan. Kekuatan organisasi, kekuatan lembaga di satu sisi dan pembangunan kerja sama di sisi yang lain dapat dibentuk dan dipertahankan dengan pembangunan prinsip saling percaya (trusting).

Masalahnya, jaringan politik sering dipakai untuk tujuan negatif. Jaringan dipakai tidak saja untuk memertahankan kekuasaan, tetapi mencari dan menumpukan modal sedapat mungkin. Implikasinya, semangat menjaga kepercayaan publik atas amanat yang dipegang oleh mereka yang akan duduk di singgah sana kekuasaan menjadi sulit terwujud.

\section{METODE}

Kajian ini menggunakan metode kualitatif. Data diperoleh dengan kajian kepustakaan. Proses pengambilan data dilakukan dengan mengkaji beberapa literatur terkait hoaks, politik, dan risiko masyarakat modern. Data-data yang sesuai dikumpulkan dan dianalisis.

\section{HASIL DAN DISKUSI \\ Efek Buruk Delegitimasi Politik}

Realitas seperti yang terjadi di atas sebenarnya masuk dalam kategori fenomena post-politik. Fenomena ini berkaitan dengan kemampuan elite politik untuk memanipulasi dan mengeluarkan politik dari watak aslinya.

Oleh elite politik kita, politik memang jarang digunakan untuk tujuan pencapaian tujuan politik yang luas (merumuskan kebijakan). Politik dimanfaatkan hanya untuk kepentingan kekuasaan semata. Karena itu, elite politik menggunakan beragam cara untuk mendapatkan kekuasaan (Cohen, 1981).

Di sana, kita dapat memahami praktik manipulasi kebenaran politik oleh elite politik. Kasus penolakan warga atas kunjungan kandidat wakil presiden, Sandiaga Uno di Labuan Bajo, Flores, Nusa Tenggara Timur beberapa waktu lalu, mendapatkan kepenuhannya di sini.

Untuk dan atas nama kekuasaan, semua cara dipakai dan segala upaya dikerahkan. Yang terjadi ialah politik keluar dari watak dan tujuan aslinya. Politik kemudian menjadi instrumen memproduksi dan mereproduksi kebohongan dan manipulasi.

Akibatnya, tujuan utama politik jauh berbeda dalam praktiknya di lapangan. Jika sudah berbeda seperti itu, yang ada hanyalah bongkahan kosong wacana politik. Politik sebenarnya bukan politik. Politik kemudian diubah menjadi mesin pencipta hoaks dan berita bohong. Politik menjadi apolitik. Sebab, realitas yang muncul tidak lagi berhubungan sama sekali dengan politik.

Hal ini patut disesalkan. Sebab, masyarakat sebenarnya menginginkan adanya realitas baru dalam politik nasional. Masyarakat Indonesia menginginkan lahirnya kampanye ide dan gagasan.

Di situ, format politik perlu diperiksa. Mekanisme politik bermartabat mesti segera dirumuskan dan harus dipraktikkan. Mekanisme tersebut, termasuk mekanisme kampanye, harus pula disertai dengan indikator yang jelas.

Hal itu mesti diikuti dengan model kontrol dan punishment yang ketat kepada elite politik yang mempertontonkan sinetron politik murahan. 
Teguran saja tidak cukup. Pelanggaran sejatinya dihadapkan dengan proses hukum yang ketat dan adil. Tanpa itu, politik kita berisi pepesan kosong. Politik nasional berwarnakan sandiwara tanpa makna. Delegitimasi politik ujung akhirnya.

Delegitimasi politik menjadi pelajaran penting yang mesti diingat pada saat memilih nanti (Jorg Kuhnelt, Eds., 2008). Memilih mereka yang gemar menyebar hoax dan mempertontonkan sinetron politik atau yang mengusung tema politik bermartabat. Kecerdasaan politik amat diperlukan di sana.

\section{Posisi Negara-Bangsa}

Posisi negara-bangsa perlu dikaji dan laik didiskusikan ketika menyebut hoaks, berita bohong, dan ujaran kebencian. Didiskusikan karena beberapa hal negatif itu tidak saja hadir di tengah perjalanan bangsa tetapi juga, jika tidak dikontrol, dapat menyebabkan negara-bangsa mati (Everard, 2000).

Menurut Everard, dunia maya harus disebut ketika mendiskusikan beragam bentuk hoaks, berita bohong, dan ujaran kebencian itu. Sebab, yang terjadi selama ini, wujud perilaku negatif masyarakat tersebut masif disiarkan oleh media masa dalam banyak jaringan.

Dengan kata lain, realitas kebohongan dan ujaran apa pun di dunia sosial, menjadi fatal ketika direproduksi dalam dunia 'dalam jaringan' (online). Ketika hoaks, berita bohong, dan ujaran kebencian berpengaruh besar pada masyarakat, kebenaran di titik yang lain semakin tersingkir.

Dalam kerangka itu, benar yang disampaikan Brenner (2009). Dalam Cyberthreats: The Emerging Fault Lines Of The Nation State, Brenner menyebutkan bahwa dunia maya sebagai zombie penyebar tidak hanya ketakutan tetapi juga kebohongan, ketidakjelasan, dan anomali.

Realitas itu berdampak pada munculnya ancaman keterpecahan negara bangsa. Masyarakat tidak hanyahidup dalam ketidakteraturan tetapi juga tumbuhnya gejala fragilitas (keterpecahan). Dengan demikian, sumbangan utama ketidaksehatan dunia maya berdampak langsung pada kehidupan sosial kemasyarakatan.

Hoaks politik, berita bohong, dan ujaran kebencian memang tidak muncul di ruang hampa. Ketiganya datang dalam langgam kondisi tertentu. Di sana, liberalisasi politik dan ekonomi dituduh sebagai agen utama munculnya perilaku buruk masyarakat.

Menurut Wissenburg (2008), liberalisasi politik menyebabkan masyarakat masuk dalam kubangan fragmentatif. Persaingan politik yang tidak sehat membuat banyak orang menggunakan beragam cara untuk mendapatkan kekuasaan.

Dengan begitu, kedaulatan sebuah negarabangsa menjadi sungguh dipertaruhkan. Sebab, setiap elemen pasti bekerja dan berjuang dengan menggerakan semua potensi yang ada. Semua pihak akan menggunakan semua peluang, baik dan buruk, untuk mendapatkan kekuasaan.

\section{Bangsa Beradab}

Indonesia merupakan bangsa beradab. Beradab karena Indonesia telah melewati fase praliterer. Indonesia sudah masuk ke alam sejarah, yang menempatkan tulisan sebagai indikator kemajuan.

Masalahnya, di ruang yang disebut politik liberal, banyak pihak di negara ini masih gagap dalam bertindak benar, seperti disampaikan Wissenburg di atas. Dengan kata lain, masyarakat di ruang politik liberalis masih kerap menggunakan cara-cara negatif untuk tujuan kekuasaan.

Tesis seperti ini memang perlu pembuktian. Sebab, membaca Indonesia, sulit untuk tidak mengatakan bahwa masyarakat Indonesia sebenarnya sudah melek huruf. Di Indonesia, yang belum bisa beranjak dari dunia prasejarah sebenarnya elite kekuasaan dan elite politik.

Hal itu ditunjukan dengan banyaknya usaha elite politik memanipulasi dan menggerakan masyarakat bawah dengan jalan salah dan keliru untuk tujuan kekuasaan individualistiknya (White, 2010). Saya yakin benar bahwa penyebaran hoaks politik, berita bohong, dan ujaran kebencian tidak akan terjadi kalau elite yang melek huruf di republik ini memberi contoh literasi positif.

Persoalannya, banyak pihak di negara ini cenderung menggunakan hoaks, berita bohong, dan ujaran kebencian untuk kepentingan kekuasaan. Karena itu, masyarakat akar rumput dibawa-bawa 
dan diseret masuk ke alam sosial dan alam maya untuk menyebar beragam contoh negatif.

Pilihan saat ini ialah ingin agar bangsa ini tetap ada atau menjadi bangsa pura-pura dalam segala hal. Yang jelas, setiap pilihan menuntut adanya tuntutan lain di belakangnya. Pilihan keutuhan bangsa menuntut semua pihak untuk segera meninggalkan penyebaran hoaks, berita bohong, dan ujaran kebencian.

Meminjam pernyataan Presiden Jokowi, semua pihak harus segera berhijrah dari ujaran kebencian ke ujaran kebenaran. Setiap pernyataan kebenaran merupakan hasil olahan jiwa dan pergumulan batiniah karena didukung oleh asupan fakta-fakta empiris yang sangat obyektif sifatnya.

Sebaliknya, jika ingin agar bangsa dan negara ini hancur, semua pihak membiarkan hoaks, berita bohong, dan ujaran kebencian terus berkembang di masyarakat. Implikasinya, kita semua tinggal menunggu lonceng kematian bangsa dan negara. Catatan pentingnya ialah bahwa semua orang Indonesia tidak rela bangsa dan negara Indonesia hancur. Masyarakat Indonesia ingin terus hidup bahkan menjadi lebih hebat dan besar.

\section{Indonesia Pascapolitik}

Membaca Indonesia dalam konteks politik, sulit untuk tidak menyebut risiko seperti pandangan kritis di atas. Disebutkan, kegaduhan ruang sosial Indonesia disebabkan karena masyarakat hidup di ruang modernitas yang amat kompleks.

Realitas itu berkembang bersamaan dengan minimnya pemahaman banyak pihak akan risiko penggunaan media sosial (Newey, 2001). Karena itu, ketika pemicu yang disebut politik kekuasaan masuk di dalamnya, hoaks terjadi dengan amat banal.

Di sana, masyarakat Indonesia kehilangan identitas sebagai bangsa. Seperti disampaikan oleh kaum berpandangan psikologi sosial di atas, manusia Indonesia pascapemilu adalah manusia yang kehilangan identitas diri karena produk yang dihasilkannya.

Bayangan bahwa Indonesia adalah bangsa besar yang terdiri dari banyak suku, kelompok, etnis, dan golongan seakan raib ditelan nafsu kekuasaan. Secara sosial dan budaya, masyarakat menjadi bangsa kerdil. Sebab, praktik politik kekanak-kanakanlah yang sering dilakukan.

Banyak elemen bangsa lupa akan risiko besar penggunaan media sosial. Bangsa ini gagal membaca bahwa politik itu amat temporer. Bangsa ini tidak berpikir bahwa Indonesia sebagai sebuah realitas sosial dan budaya telah ada jauh sebelum politik kenegaraan hadir di sini. Yang menguasai manusia Indonesia ialah kemauan untuk menjadikan manusia lain musuh dan lawan.

Ketika hoaks berhasil memecah belah bangsa ini, rezim modernitas adalah pihak yang paling beruntung. Modernitas tidak peduli risiko yang terjadi. Intinya, media sosial yang diproduksinya sukses. Sukses dalam kategori ini tentu dalam pengertian kesuksesan sebagai alat masyarakat, entah seperti apa penggunaan alat itu oleh masyarakat modern.

Bangsa Indonesia akan terus menjadi bangsa berisiko jika tidak segera sadar. Kesadaran harus tertuju ke dua arah sekaligus. Ke dalam, masyarakat harus segera sadar bahwa bangsa ini terlampau mahal jika dikorbankan hanya karena politik sesaat. Bayangan kejayaan Indonesia dulu, yang terdiri dari beragam etnis, suku, agama, dan golongan harus terus dibangun.

Keluar, manusia Indonesia harus segera berpikir bahwa modernitas selalu membawa dua implikasi sekaligus, berkat dan kutukan; setan dan lucifer. Jika ingin agar bangsa ini mendapatkan berkat media sosial, gunakan media sosial secara cerdas. Sebaliknya, jika ingin bangsa ini hancur berantakan, segeralah mengamini kerja destruktif modernitas.

\section{Kontrol Diri}

Fenomena risiko seperti yang digambarkan di atas merupakan fakta banal atas semua ketakutan yang ditimbulkan oleh perkembangan ilmu dan teknologi. Semua kita bisa merasakan fenomena itu sampai saat ini. Saat ini, semua kita merayakan keterbukaan tetapi sekaligus dihantui oleh beragam ketakutan.

Beck menawarkan solusi atas semua risiko tersebut dengan rumusan politis. Yang dimaksudkan adalah adanya kemauan pengambil kebijakan dan terutama negara untuk selalu mengontrol kerja 
modernitas. Beck menginginkan agar negara harus kuat ketika berhadapan dengan modal. Negara harus menjadi guru yang bisa mengajarkan masyarakat akan dampak dan risiko negatif teknologi.

Media sosial misalnya merupakan salah satu bentuk produk modernitas manusia modern. Seperti yang telah dijelaskan di bagian awal di atas, masalah utama manusia modern adalah ketika menganggap bahwa dunia ini merupakan ruang terbuka. Karena terbuka maka semua orang boleh mengungkapkan apa saja di media, terutama media sosial.

Di sini harus disebut pengetahuan dan kecerdasan manusia. Menurut saya, media sosial bisa diketahui oleh siapa pun. Media sosial adalah alat untuk membantu pekerjaan manusia modern. Masalahnya, manusia modern tidak memiliki cukup alat untuk mengontrol sikap dan perilakunya di dunia sosial.

Dalam konteks itu, mulut dan kata harus pula dijelaskan. Jika boleh didefinisikan dengan agak bebas, kata adalah deretan huruf yang bisa memiliki arti tertentu sedangkan mulut adalah salah satu alat fisik untuk mengungkapkan kata itu. Pertanyaannya, apakah hanya dua alat itu yang dibutuhkan dalam media sosial?

Banyak ahli telah menjawab pertanyaan singkat tersebut. Jawabannya ialah dua alat itu belum cukup mengontrol mulut dan kata. Pikiran dan perasaan (emosi) harus pula disebut. Menjaga kata untuk tidak asal diucapkan ke publik, tentu harus menyertakan kekuatan pikiran dan dorongan perasaan seseorang. Ini menyangkut kemampuan seseorang untuk mengontrol pikiran dan perasaan. Masalah terbesar masyarakat saat ini adalah realitas kehilangan kontrol penggunaan media, kontrol diri dan sosial. Itulah guna dan manfaat nilai-nilai sosial, budaya, adat dan juga agama.

Untuk konteks media sosial, nilai-nilai yang terkandung di beberapa lembaga yang disebut di atas harus menjadi perhatian semua orang. Nilainilai itu sejatinya bisa diterapkan dan dipraktikan di ruang lebar media sosial.

\section{PENUTUP}

Kebohongan hanya dapat dilawan dengan terus mempromosikan kejujuran. Dengan demikian, politik kebohongan hanya bisa diminimalisasi dengan terus mengkampanyekan politik kejujuran.

Politik kejujuran tentu tidak hanya menjadi tugas lembaga politik lain. Politik kejujuran harus menjadi semangat bersama dan mesti menjadi cara hidup manusia politik.

Mengatasi dan melawan politik kebohongan tentu tidak bisa hanya mengandalkan piranti nilai, etika dan moral. Dibutuhkan perangkat lain di sana.

Maka, gerakan mendidik masyarakat agar semakin kritis dalam politik menjadi keniscayaan. Itu berarti, pemerintah wajib didukung oleh elemen pendidikan dan lembaga sosial lainnya. Itulah yang disebut gerakan literasi politik.

Gerakan literasi politik ialah usaha komprehensif yang melibatkan semua pihak dan elemen secara intens dan terus-menerus dalam memerangi kebohongan. Selain nilai dan norma, piranti hukum, sosial dan keagaman perlu dimasukan di sana.

Politik kebohongan harus dianggap sebagai bencana sosial di ruang politik. Karena itu, dibutuhkan usaha bersama memerangi politik yang sarat dengan kebohongan. Solidaritas sosial masyarakat menjadi penting dan urgen.

Tanpa itu, ruang politik kita akan terus dihiasi beragam kebohongan. Masyarakat kita akhirnya menjadi entitas yang menjalankan hidup dengan nilai kebohongan pula. Sebuah bentuk pendidikan politik yang buruk untuk generasi Indonesia mendatang. Aktornya ialah elite politik masa kini.

Di sini, literasi media sosial itu baru mendapatkan kepenuhan jika semua pihak bergerak mulai dari kesadaran diri. Jika hal itu tidak dilakukan, bangsa ini akan hidup dalam alam risiko berkepanjangan.

\section{Bibliografi}

Adejumobi, Said. 2011. State, Economy, and Society in Post-Military Nigeria. Palgrave Macmil lan

Baudrillard, Jean. 1983. Simulacrum. Semiotext(e), Inc.

Beck, Ulrich, Scott Lash, Brian Wynne. 1992. Risk Society: Towards a New Modernity. 
SAGE Publications. USA.

Brenner, W Susan. 2009. Cyberthreats: The

Emerging Fault Lines Of The Nation State.

Oxford University Press.

Cohen, Abner. 1981. The Politics of Power Culture. University of California Press. Berkeley. Los Angeles. London

Everard. 2000. Language, Power and Identity Politics. Springer.

Farrel, Henry. 2009. The Political Economy of Trust. Cambridge University Press.

Jorg Kuhnelt (Eds.). 2008. Political Legitimization without Morality?. Springer

Science+Business Media B.V. Mafindo, September 2018.

Newey, Glen. 2001. After Politics: The Rejection Of Politics In Contemporary Liberal Philosophy. Palgrave Macmillan.
Ramamurthy, V and Shanze, Kirk S., 2001. Understanding and Manipulating ExcitedState Processes. Marcel Dekker, Inc.

Runciman. 2008. Political Hypocrisy: The Mask of Power, From Hobbes to Orwell and Beyond. Paperbac.

Tilly, Charles. 2005. Trust and Rule. Cambridge University Press

Weaver, Catherine. 2008. Hypocrisy Trap: The World Bank and The Poverty of Reform. Paperback.

White, Adam. 2010. The Politics of Private Security: Regulation, Reform and Re-Legitimation. Palgrave Macmillan

Wissenburg, Marcel. 2008. Political Pluralism and the State: Beyond Sovereignty. Routledge Innovators in Political Theory. London: Routledge. 